\title{
Comments on "ESR dating of the Majuangou and Banshan Paleolithic sites in the Nihewan Basin, North China" by Liu et al. (2014)
}

\author{
Mathieu Duval a, b \\ a Program of Geochronology, Centro nacional de investigación sobre la evolución humana (CENIEH), Spain
}

${ }^{\mathrm{b}}$ Research School of Earth Sciences, The Australian National University, Australia

\section{A R T I C L E I N F O}

Article history:

Received 30 October 2014

Accepted 27 April 2015

Available online $\mathrm{xxx}$

\section{Introduction}

Liu et al. (2014) recently published an ESR dating study of two palaeolithic sites, Majuangou and Banshan, from the Nihewan Basin (China), based on the use of the Ti-Li paramagnetic center measured in optically bleached quartz grains. The authors collected between two and five sediment samples per site and final ESR age results shown in their Table 1 are internally highly consistent for a given site, with a relative scatter (coefficient of variation) varying between $1.3 \%$ (BS samples) and 4.3\% (MJG-1 samples). In addition, these ESR age estimates are overall in good agreement with the previous chronological estimation derived from an interpolation of the sedimentation rate based on magnetostratigraphic data (Zhu et al., 2004): the relative offset of the mean ESR ages for a given site ranges between $-9.0 \%$ (MJG-I samples) and +5.5\% (MJG-III samples), but $11 /$ 13 of the ESR age results are consistent at $1 \sigma$ with the expected age, and all of them are consistent at $2 \sigma$. These excellent results logically lead the authors to conclude that "ESR dating could be effectively applied to establish an independent whole chronology model for the early human sites in the Nihewan Basin to contribute to a better understanding of early human occupation in the high northern latitudes of East Asia“(Liu et al., 2014: 62).

Moreover, a previous paper by Liu et al. (2013) presented the results of another ESR dating study, on the Donguttuo Palaeolithic site, also located in the Nihewan Basin, and using a similar methodology. Again, ESR age estimates $(n=4)$ based on the Ti-Li center were all internally consistent (coefficient of variation $=4.1 \%$ ), and

DOI of original article: http://dx.doi.org/10.1016/j.jhevol.2014.05.012.

E-mail address: mathieu.duval@cenieh.es. in excellent agreement with the existing chronostratigraphic framework suggesting a pre-Jaramillo age ( $>1.07 \mathrm{Ma})$ for the site. From those results the authors concluded "that the reliable ESR dating range of bleached quartz using $\mathrm{Ti}-\mathrm{Li}$ centre can be effectively extended to $1100 \mathrm{ka}$ [...]." (Liu et al., 2013: 348).

At first glance, as mentioned by the authors, such promising results could be considered as a clear demonstration of the accuracy that may be afforded by the Ti-Li center for Early Pleistocene samples and may thus be cited in the future among the best case studies establishing the great potential of ESR dating applied to optically bleached quartz grains. However, a careful reading of the work by Liu et al. (2014) raises many questions regarding the exact meaning and the reliability of the ESR age estimates that have been obtained, and therefore the validity of the archaeological interpretation that may be derived from them. The purpose of my paper is not to question the existence of these Palaeolithic occupations in the Nihewan Basin, or their estimated chronology (for this purpose, the reader should see Dennell, z015), nor is it intended to discuss the reliability of the ESR dating method for this time range. It is rather to highlight some potential issues with the dating work performed at these sites. In my opinion, the apparent robustness and consistency of the dating results actually hides some weaknesses in the methodology, which may be reasonably questioned in two ways: (i) some basic information regarding the experimental conditions, data analysis and age calculation are missing and (2) the analytical procedure seems to be biased in some aspects, which may have a major impact on the final data, and result in significant age overestimations.

\section{Estimation of the $D_{E}$ values based on the Ti-Li center}

The main issue in the results shown by Liu et al. (2014) lies in the evaluation of the equivalent dose $\left(D_{E}\right)$ values based on the use of the Ti-Li signal. However, some important data related to the fitting are simply not reported (such as the software that has been used, whether the data have been weighted and how $D_{E}$ errors were calculated) but the selection of the fitting function is undoubtedly the key point that should be discussed as a matter of priority. When using the additive dose method for ESR dose reconstruction, the $D_{E}$ values are by definition obtained by back extrapolation of the fitting function to the X-axis. Consequently, the 
Table 1

ESR age estimates and associated data obtained for samples S3 from Donguttuo.

\begin{tabular}{llccc}
\hline & Sample & $\begin{array}{c}\text { Total dose rate } \\
(\mu \mathrm{Gy} / \mathrm{a})\end{array}$ & $\mathrm{D}_{\mathrm{E}}(\mathrm{Gy})$ & ESR age (ka) \\
\hline A & S3 & $3174 \pm 195$ & $3564 \pm 405$ & $1127 \pm 146$ \\
B & S3 & $3174 \pm 195$ & $1630 \pm 263$ & $514 \pm 89$ \\
$\mathrm{C}$ & $\mathrm{S} 3$ & $3174 \pm 195$ & $1480 \pm 305$ & $466 \pm 100$ \\
\hline
\end{tabular}

Line A: original data from Liu et al. (2013); Line $\mathrm{B}$ : $\mathrm{D}_{\mathrm{E}}$ value is derived from the fitting of a SSE function (Fig. 1), with data weighted by $1 / \mathrm{I}^{2}$; Line C: $\mathrm{D}_{\mathrm{E}}$ value is derived from the fitting of a SSE function (Fig. 1), without data weighting.

choice of the fitting function has a direct and significant impact on the $D_{E}$ estimates (e.g. Duval et al., 2009), surely more important than with the regenerative dose approach, for which the $D_{E}$ is obtained by interpolation between two points (e.g. Aitken, 1998). Actually, a fitting function should not only describe the behaviour of the ESR signal with the absorbed dose, but also have some physical basis (see Duval et al., 2009 and reference therein). To fit the experimental ESR data points, Liu et al. (2014) used a fitting function made by a combination of an exponential plus a linear term (EXP + LIN). This function is usually employed for ESR Dose Response Curves (DRC) with an almost linear increase at high doses (e.g. Duval, 2012). To support this choice, they mention previous work such as Duval et al. (2009, 2011) and Duval (2012) that suggested the use of an alternative function instead of the classically used SSE. However, these ESR dating studies were based on either tooth enamel (Duval et al., 2009) or on the Al center in quartz (Duval et al., 2011; Duval, 2012). In other words, none of them was about the Ti center, whereas it is known that each paramagnetic center has a very specific response to the irradiation dose. In that regard, it has been demonstrated that the intensity of the Ti center shows a non-monotonic behaviour with the irradiation dose (Woda et $\mathrm{at}_{2,}$ 2007; Duval and Guilarte, 2015), which means the ESR intensity starts decreasing at high doses, usually > 7-10 kGy depending on the samples. Obviously, there may be some variability from one sample to another, but so far an almost linear positive behaviour at high dose similar to that of the Al center has never been observed for the Ti center (Duval and Guilarte, 2015). Therefore, there is no apparent reason for the use of an EXP + LIN function and the authors do not show any ESR DRC to support their choice. In fact, two fitting functions may classically be used with the $\mathrm{Ti}-\mathrm{Li}$ center, both yielding roughly similar results, either a SSE function or the so-called Ti-2 function, depending on the magnitude of the maximum irradiation dose (see Duval and Guilarte, 2015): for the data from Liu et al. (2014) aliquots were irradiated up to $10 \mathrm{kGy}$, a dose region where ESR intensities should be close to their maximum, which indicates that, in theory, a SSE function should preferentially be used (Duval and Guilarte, 2015).

Unfortunately Liu et al. (2014) do not show any ESR DRC of the 13 samples analysed, which basically makes it impossible for the reader to visualize the evolution of the ESR intensity of the $\mathrm{Ti}-\mathrm{Li}$ center at high doses as well as to have a clear idea of the quality of the ESR data set (and thus of the ages that are derived). To get further insights into the potential bias induced by the use of a EXP + LIN function instead of an classic SSE, the only solution lies in using the paper by Liu et al. (2013), where the authors used the same methodology. In that work, they actually do show a DRC for one sample (S3; Fig. 4 from Liu et al., 2013). At first glance, several issues may be observed. First, there is apparently a saturation of the signal at doses $>4 \mathrm{kGy}$; since the last three points show very similar ESR intensities, which is similar to what is ustally observed in other samples (Duval and Guilarte, 2015). Such an observation would definitely be in favour of the SSE function, and the use of an EXP + LIN function instead is hardly understandable. Second, the fit of this function is apparently not good: the function does not go through most of the experimental points. In particular, the function goes well above the natural and first irradiated aliquot, which may lead to an overestimation of the $D_{E}$ value. But the main source of overestimation comes from the linear back extrapolation. Such a linear back extrapolation has never before been used on quartz, and is not recommended for materials showing an apparent single saturating exponential behaviour (see Grün, 1996). In reality, the fitting function shown in Fig. 4 from Liu et al., 2013 can simply not be the EXP + LIN function described by the equation $\mathrm{I}(\mathrm{D})=\mathrm{I}_{\mathrm{sat}}{ }^{*}(1-$ $\left.\exp \left(-\mu\left(D+D_{E}\right)\right)\right)+B^{*}\left(D+D_{E}\right)$ given in Liu et al. $(2013,2014)$, since the linear term is for high doses and not for the back extrapolation (e.g. Duval, 2012). It seems instead that the authors have somehow inverted the function, with a linear term for the low dose range and back extrapolation, and an exponential saturating term for the high dose range.

Data points were extracted from Fig. 4 of Liu et al. (2013) to run a new fitting with the OriginPro 8.5 software, using both SSE and EXP + LIN functions and data weighted by the inverse of the squared intensities $\left(1 / \mathrm{I}^{2}\right)$. Further details about this standard fitting procedure may be found in Duval (2012). Results are shown in Fig. 1 and numerical values are given in Table 1. First of all, it is worth mentioning that an EXP + LIN function could simply not be fitted through the ESR data, since the three last points do not show any increasing linear trend. Then, the use of the SSE function yields a $D_{E}$ value of $1630 \pm 263 \mathrm{~Gy}$, i.e. less than half of the value obtained by Liu et al. (2013) (3564 $\pm 405 \mathrm{~Gy})$. Adjusted $\mathrm{r}^{2}$ is of 0.977 and thus shows a regular to poor goodness-of-fit given the scatter of the ESR data points, which is below the standards to ensure reliable $D_{E}$ values (Duval and Guilarte, 2015). To summarize, as could be expected from a visual observation of Fig. 4, the function used in Liu et al. (2013) provides a massive $D_{E}$ overestimation, by a factor of 2.2. Consequently, the ESR age of sample S3 was recalculated with this new $D_{E}$ value (and using the total dose rate value given by Liu et al., 2013), yielding a result of $514 \pm 89 \mathrm{ka}$ instead of $1127 \pm 147 \mathrm{ka}$. This new age estimate is significantly younger than the assumed preJaramillo age of the Donggutuo site, and is consequently no longer consistent with the existing chronostratigraphic framework. Given this result, the use of this pseudo-EXP + LIN function to fit the ESR data set raises many reasonable doubts about the reliability of the ESR ages presented in Liu et al. (2013, 2014). It is virtually impossible to evaluate the magnitude of this bias for the rest of the samples analysed in these two papers, since no more ESR data are provided by the authors, but it is nevertheless highly probable that all these ESR age estimates are strongly overestimated.

Last, data weighting is another crucial parameter (although, to a somewhat lesser extent than the selection of the function) that must be taken into account during the fitting, especially when using the additive dose method. It is usually recommended to weight the data by $1 / \mathrm{I}^{2}$ (see Grün and Brumby, 1994) to reduce both systematic and random errors. In that regard, Liu et al. $(2013,2014)$ do not mention anything on this point, suggesting that they did not use any weighting procedure. To evaluate the impact of this parameter on the final $D_{\mathrm{E}}$ value, an additional fitting procedure was carried out with OriginPro 8.5 software without data weighting (Fig. 1 and Table 1 ). A $D_{\mathrm{E}}$ value of $1480 \pm 305 \mathrm{~Gy}$ was obtained, i.e. $\sim 9 \%$ lower than the previous $D_{E}$ obtained with weighting by $1 / \mathrm{I}^{2}$, but nevertheless in agreement at $1 \sigma$. Consequently, the resulting ESR age estimate is within the margins of error of the other recalculated age (Table 1).

\section{Evaluation of the dose rate}

To a lesser extent, the evaluation of the dose rate made by Liu et al. (2014) also raises some questions. Fluvio-lacustrine deposits 

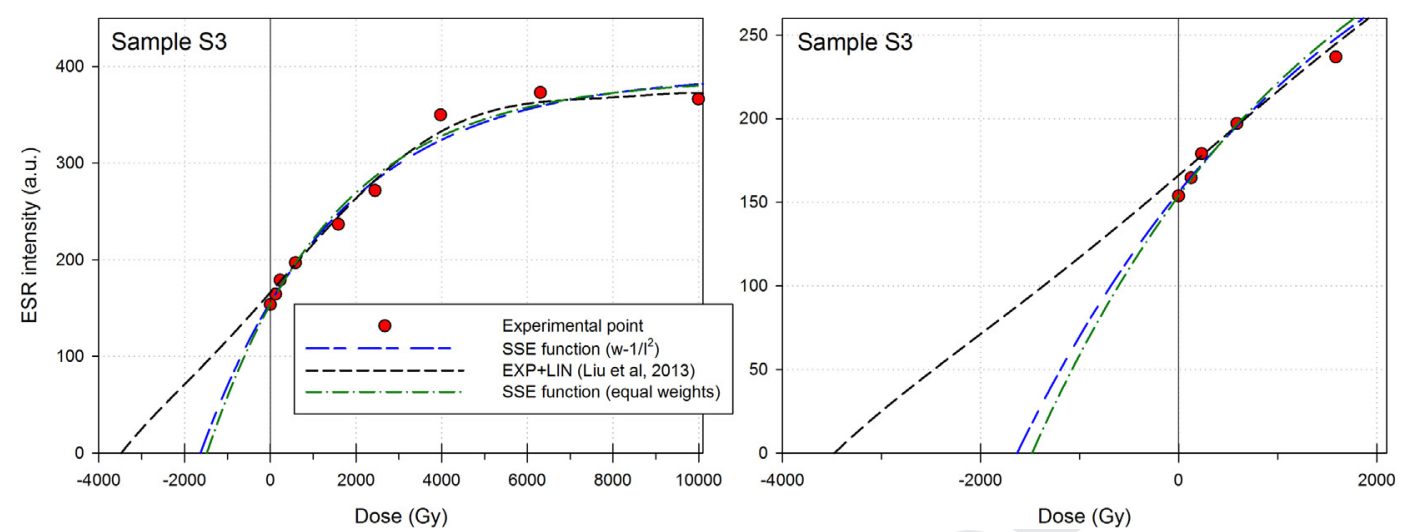

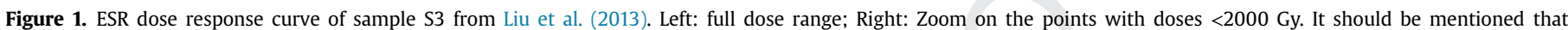

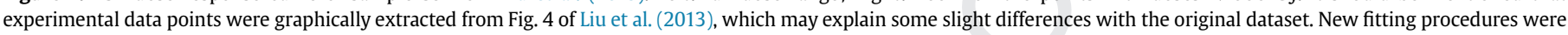
carried out using a SSE function with and without data weighting.

are not known for their homogeneity and the absence of in situ gamma dose rate measurements is thus potentially an issue. The total dose rate is directly assessed from the radioelement concentration based on alpha counting for $U$ and Th, and by Atomic Absorption for $\mathrm{K}$. If these techniques are commonly used for the evaluation of the external alpha and beta dose rate components, their suitability for assessing the gamma dose rate may reasonably be questioned. Indeed, these two techniques require only a few grams of sediment, and it is very unlikely this amount is representative of the whole sedimentary environment surrounding the sample point in a $30-\mathrm{cm}$ radius sphere. So far, the only way to minimize this uncertainty without any in situ measurements is to collect several sediment samples in order to evaluate the lateral and vertical variations of the radioactivity in the immediate surrounding environment, but nothing is mentioned about this issue in Liu et al. (2014): the total dose rate is systematically derived from only one single sediment sample for all the samples of a given archaeological layer.

Unfortunately, only the total dose rate values are shown in Table 1 in Liu et al. (2014), while those calculated for the various components of this dose rate are not given in the manuscript. The authors assume the internal dose rate to be negligible, but then there is no mention about the external alpha component. In addition, the assumed/estimated thickness that has been removed from the grains by the etching is not specified, which is definitely crucial information for alpha and beta attenuation values. Nevertheless, the external alpha component is extremely likely to be very small given the concentration (40\%) of the HF and the long duration (100 $\mathrm{min}$ ) of the etching. From previous studies, a thickness of about $40 \mu \mathrm{m}$ removed by HF etching could be estimated (Duval et al., 2014), which would make the alpha attenuation value close to 0 (Brennan et al., 1991). Conversion and correction factors for dose rate calculation are also subject to some questions. Dose rate conversion factors were taken from Aitken (1985) without further explanation, while they have been continuously updated over the last decades (e.g. Adamiec and Aitken, 1998; Guérin et al., 2011). Since water content has been estimated to be $10 \%$, it seems that water attenuation has been taken into consideration but, again, this is not specified and there is no reference to the equation that has been used for this purpose. Finally, beta attenuation is estimated to be 0.9 but there is no mention where these attenuations are taken from, and this value is probably overestimated given the duration of the HF etching. In addition, given that the authors have the specific concentrations for each radioelement, they should have calculated specific beta attenuations for each element (Brennan, 2003). Finally, there is no indication about how dose rate errors have been calculated. Radioelement concentrations are provided without any associated errors, as well as total dose rate values, unlike $D_{E}$ ones (see subsection 1.1. in Liu et al., 2014). Actually, relative age errors are somewhat low (between $6.0 \%$ and $13.7 \%$ at $1 \sigma$ ), and very likely underestimated. For most of the samples, these age errors are just the same as the relative $D_{E}$ errors: the error on the total dose rate has apparently been simply ignored in the final age calculation.

Given the number of questions that have been raised regarding the evaluation of the dose rate by Liu et al. (2014), new calculations were performed with a non-commercial SCILAB based program. Final errors $(1 \sigma)$ were derived from Monte Carlo simulations based on individual errors derived from radioelement concentrations, water content, grain size and alpha efficiency. The following parameters were used:

- An error of $5 \%$ was assumed on the radioelement concentrations values indicated in Table 1.

- Dose rate conversion factors were taken from Guérin et al. (2011).

- Initial mean grain size was assumed to be of $150 \mu \mathrm{m}$ and the removed thickness of the outer part of the grain by HF etching was estimated to be $40 \mu \mathrm{m}$.

- A water content of $10 \pm 5 \%$ was considered.

- Alpha, beta and water attenuations values were from Brennan et al. (1991), Brennan (2003) and Grün (1994), respectively.

- An alpha efficiency k of $0.15 \pm 0.10$ was assumed (Yokoyama et al., 1985)

- Internal and cosmic dose fate were assumed to be negligible.

- U-238 series in sediment was assumed to be in equilibrium.

Results are listed in Table 2. New total dose rate values are all lower than those from Liu et al. (2014) by $11 \%$. If a small dose rate of $50 \mu \mathrm{m}$ is assumed, as is sometimes the case (e.g. Duval et al., 2015), the deviation would decrease slightly to $9 \%$. Relative errors on the total dose rates are around $8 \%$, which means that both data sets would probably be consistent at $1 \sigma$ if the previous values had associated errors. Such a systematic deviation very likely comes from some differences in the correction factors, in relation to the beta dose attenuations and/or the water content corrections. However, the absence of relevant details in Liu et al. (2014) precludes any further interpretation.

\section{Summary}

To summarize, the $D_{E}$ results obtained by Liu et al. $(2013,2014)$ seem to be strongly overestimated, mainly because of the selection 
Table 2

Comparison of the dose rate values from Liu et al. (2014) with those from the new calculations performed in the present work. Details may be found in the text.

\begin{tabular}{|c|c|c|c|c|c|c|}
\hline \multirow[b]{2}{*}{ Samples } & \multirow[b]{2}{*}{$\mathrm{D}_{\alpha}$} & \multicolumn{2}{|c|}{ This work } & \multirow[b]{2}{*}{$\mathrm{D}_{\text {total }}$} & \multicolumn{2}{|c|}{ Liu et al. (2014) } \\
\hline & & $\mathrm{D}_{\beta}$ & $\mathrm{D}_{\gamma}$ & & $\mathrm{D}_{\text {total }}$ & Ratio \\
\hline BS- 1 to 5 & $13 \pm 13$ & $1573 \pm 128$ & $991 \pm 73$ & $2577 \pm 205$ & 2890 & 0.89 \\
\hline MJG-I-1 to 3 & $13 \pm 13$ & $1857 \pm 153$ & $1099 \pm 80$ & $2969 \pm 235$ & 3330 & 0.89 \\
\hline MJG-II- 1 to 2 & $10 \pm 11$ & $1487 \pm 121$ & $873 \pm 63$ & $2370 \pm 190$ & 2650 & 0.89 \\
\hline MJG-III- 1 to 3 & $8 \pm 9$ & $1581 \pm 132$ & $835 \pm 61$ & $2424 \pm 198$ & 2710 & 0.89 \\
\hline
\end{tabular}

$D_{\alpha}, D_{\beta}, D_{\gamma}$ and $D_{\text {total }}$ are the external alpha, beta and gamma dose rates, and total dose rates, respectively. Errors are given at $1 \sigma$.

of an inappropriate fitting function. In an attempt to quantify the magnitude of this overestimation, the ESR data available for one sample were re-analysed, yielding a new $D_{E}$ value lower by more than half of the value initially obtained by the authors. This may provide a fair idea of the bias induced by the pseudo-EXP + LIN function that has been used in both papers even though, unfortunately, the absence of ESR data precludes any further estimation for the other samples. Similarly, a recalculation of the dose rates obtained by Liu et al. (2014) provides results that are systematically lower by about $11 \%$ but are, nevertheless, very likely consistent with the previous values, leaving aside the uncertainty associated with possible lateral variations in the radioactivity that may strongly influence the gamma dose rate. The combination of these two observations thus suggests that the ESR age estimates obtained are significantly overestimated. This implies that correct ESR age estimates are probably systematically and significantly younger than the expected chronology of the sites. However, in the absence of the minimum information required to perform new age evaluations and quantify this difference more accurately, any further interpretation would be pure speculation.

\section{Concluding remarks}

To address the inconsistency between the re-calculated ESR age results and the expected chronology of the sites, some avenues would be worth exploring in the future, such as the evaluation in situ of the gamma dose rate at the exact location where the samples were collected, or to check for potential disequilibrium in the U-238 series of the sediment. Following the principles of the multiple center method proposed by Toyoda et al. (2000), it would be also especially interesting to measure the ESR signal associated with the Al center for all these samples, since this center has already shown its potential for dating Early Pleistocene deposits (e.g. Duval et al., 2015; Voinchet et al., 2010). The comparison of the ESR age results derived from both $\mathrm{Ti}$ and $\mathrm{Al}$ centers should provide additional useful information to better constrain the chronology of these Palaeolithic sites.

Again, the purpose of the present work should not be misinterpreted: this is not to question in general the reliability of the ESR dating method applied to optically bleached quartz grains from Early Pleistocene deposits, but rather to point out some issues with these two specific applications to Palaeolithic sites from the Nihewan Ba$\sin$. In that regard, I would definitely encourage Liu and colleagues to provide all the required information, and especially the ESR DRCs of these samples, so that the readers can decide for themselves.

From a broader perspective, this paper also raises some important questions about the minimum information that should be documented in a paper dealing with ESR dating of optically bleached quartz grains. In a similar manner to what has been already done for many other numerical dating methods (e.g. Millard, 2014 for radiocarbon dating; Renne et al., 2009 for $\mathrm{Ar}-\mathrm{Ar}$ dating; Forman et al., 2000; Duller, 2008 for luminescence dating), efforts should be dedicated in our community to standardize the reporting of ESR dating methodology and age results based on optically quartz grains, so that readers can correctly assess their reliability and interpret their meaning.

\section{Uncited reference}

Duval and Arnold, 2013, Grün, 1989, Grün and Rhodes, 1991, Grün and Rhodes, 1992, Guérin et al., 2012, Ikeya, 1993, Liu et al. 2010, Moreno et al., 2012, Prescott and Hutton, 1988, Prescott and Hutton, 1994, Rink, 1997, Tissoux et al., 2007, Tissoux et al., 2008

\section{Acknowledgments}

I would like to thank my colleague geochronologists for sharing some useful information about their speciality, Lee Arnold (Adelaide University, Australia), Sébastien Nomade (LSCE, France) and Antoine Zazzo (MNHN, France) for luminescence, $\mathrm{Ar}-\mathrm{Ar}$ and radiocarbon dating, respectively. This work was supported by a Marie Curie International Outgoing Fellowship awarded to M.D. within the European Union's Seventh Framework Programme (FP7/ 2007-2013) under REA grant agreement n PIOF-GA-2013-626474.

\section{References}

Adamiec, G., Aitken, M.J., 1998. Dose-rate conversion factors: update. Ancient TL 16 (2), 37-50.

Aitken, M.J., 1985. Thermoluminescence Dating. Academic Press, London.

Aitken, M.J., 1998. An Introduction to Optical Dating. Oxford University Press Oxford.

Brennan, B.J., 2003. Beta doses to spherical grains. Radiat. Meas. 37 (4-5), 299-303. Brennan, B.J., Lyons, R.G., Phillips, S.W., 1991. Attenuation of alpha particle track dose for spherical grains. International Journal of Radiation Applications and Instrumentation. Part D. Nucl. Tracks Rad. Meas. 18 (1-2), 249-253.

Dennell, R., 2015. The Jaramillo Subchron, a geochronological marker horizon in the palaeoanthropological record of China. Quat. Int. http://dx.doi.org/10.1016/ j.quaint.2014.11.006.

Duller, G.A.T., 2008. Luminescence Dating: guidelines on using luminescence dating in archaeology. English Heritage, Swindon.

Duval, M., 2012. Dose response curve of the ESR signal of the Aluminum center in quartz grains extracted from sediment. Ancient TL 30 (2), 1-9.

Buval, M., Arnold, L.J., 2013. Field gamma-dose rate assessment in natural sedi mentary contexts using $\mathrm{LaBr}_{3}(\mathrm{Ce})$ and $\mathrm{NaI}(\mathrm{TI})$ probes: A comparison between the "threshold" and "windows" techniques. Appl. Radiat. Isotopes 74, $36-45$.

Duval, M., Guilarte, V., z015, ESR dosimetry of optically bleached quartz grains extracted from Plio-Quaternary sediment: evaluating some key aspects of the ESR signal associated to the Ti-center. Radiat. Meas. http://dx.doi.org/10.1016/ j.radmeas.2014.10.002.

Duval, M., Grün, R., Falguères, C., Bahain, J.J., Dolo, J.M., 2009. ESR dating of Lower Pleistocene fossil teeth: Limits of the single saturating exponential (SSE) function for the equivalent dose determination. Radiat. Meas. 44 (5-6) 477-482.

Duval, M., Moreno, D., Shao, Q., Voinchet, P., Falguères, C., 2011. Datación por ESR del yacimiento arqueológico del Pleistoceno inferior de Vallparadís (Terrassa, Cataluña, España). Trabajos Prehist 68 (1), 7-24.

Duval, M., Bahain, J.-J., Falguères, C., Garcia, J., Guilarte, V., Grün, R., Martínez, K., Moreno, D., Shao, Q., Voinchet, P., Z015. Revisiting the ESR chronology of the Early Pleistocene hominin occupation at Vallparadís (Barcelona, Spain). Quatern. Int. http://dx.doi.org/10.1016/j.quaint.2014.08.054.

Forman, S.L., Pierson, J., Lepper, K., 2000. In: Sowers, J., Noller, J., WR, L. (Eds.), Luminescence Geochronology. Quaternary Geochronology: methods and applications. American Geophysical Union, Washington, DC, pp. 157-176.

Grün, R., 1989. Electron-spin resonance (ESR) dating. Quatern. Int. 1, 65 109.

Grün, R., 1994. A cautionary note: use of 'water content' and 'depth for cosmic ray dose rate' in AGE and DATA programs. Ancient TL 12 (2), 50-51. 
Grün, R., 1996. Errors in dose assessment introduced by the use of the "linear part" of a saturating dose response curve. Radiat. Meas. 26 (2), 297-302.

Grün, R., Rhodes, E.J., 1991. On the selection of dose points for saturating exponential ESR/TL dose response curves. Ancient TL $9(3), 40-46$.

Grün, R., Rhodes, E.J., 1992. Simulations of saturating exponential ESR/TL dose response curves weighting of intensity values by inverse variance. Ancient $T$ $10(3), 50-56$

Grün, R., Brumby, S., 1994. The assessment of errors in past radiation doses extrapolated from ESR/TL dose-response data. Radiat. Meas. 23 (2-3), 307-315.

Guérin, G., Mercier, N., Adamiec, G., 2011. Dose-rate conversion factors: update. Ancient TL 29 (1), 5-8.

Guérin, G., Mercier, N., Nathan, R., Adamiec, G., Lefrais, Y., 2012. On the use of the infinite matrix assumption and associated concepts: A critical review. Radiat Meas. 47 (9), $778-785$.

Heya, M., 1993. New Applications of Electron Spin Resonance Dating, Dosimetry and Microscopy. World Scientific, Singapore.

Liu, C.R., Yin, G.M., Gao, L., Bahain, J., Li, J.P., Lin, M., Chen, S.M., 2010. ESR dating of Pleistocene archaeological localities of the Nihewan Basin, North China = Preliminary results. Quat. Geochronol. 5 (2 3), 385-390.

Liu, C.R., Yin, G.M., Fang, F., Voinchet, P., Deng, C.-L., Han, F., Li, J.-P., Song, W.-J., Wang, D., Bahain, J.-J., 2013. ESR dating of the Donggutuo Palaeolithic site in the Nihewan Basin, northern China. Geochronometria 40 (4), 348-354.

Liu, C.R., Yin, G.M., Deng, C.L., Han, F., Song, W.-J., 2014. ESR dating of the Majuangou and Banshan Paleolithic sites in the Nihewan Basin, North China. J. Hum. Evol. $73,58-63$.

Millard, A.R., 2014. Conventions for Reporting Radiocarbon Determinations. Radiocarbon 56 (2), 555-559.

Moreno, D., Falguères, C., Pérez González, A., Duval, M., Voinchet, P., BenitoCalvo, A., Ortega, A.I., Bahain, J., Sala, R., Carbonell, E., Bermúdez de Castro, J.M. Arsuaga, J.L., 2012. ESR chronology of alluvial deposits in the Arlanzón valley
(Atapuerca, Spain): Contemporaneity with Atapuerca Gran Dolina-site. Quat. Geochronol. $10(0), 418-423$.

Prescott, J.R., Hutton, J.T., 1988. Cosmic ray and gamma ray dosimetry for TL and ESR. International Journal of Radiation Applications and Instrumentation. Part D. Nucl. Tracks Rad. Meas. 14 (1-2), 223-227.

Prescott, J.R., Hutton, JT., 1994. Cosmic ray contributions to dose rates for luminescence and ESR dating: Large depths and long term time variations. Radiat. Meas. $23(2-3), 497-500$.

Renne, P.R., Deino, A.L., Hames, W.E., Heizler, M.T., Hemming, S.R., Hodges, K.V. Koppers, A.A.P., Mark, D.F., Morgan, L.E., Phillips, D., Singer, B.S., Turrin, B.D., Villa, I.M., Villeneuve, M., Wijbrans, J.R., 2009. Data reporting norms for ${ }^{40} \mathrm{Ar} /{ }^{39} \mathrm{Ar}$ geochronology. Quat. Geochronol. 4 (5), 346-352.

Rink, W.J. 1997. Electron spin resonance (ESR) dating and ESR applications in quaternary science and archaeometry. Radiat. Meas. 27 (5-6), 975-1025.

Tissoux, H., Falguères, C., Voinchet, P., Toyoda, S., Bahain, J.J., Despriée, J., 2007. Potential use of Ti-center in ESR dating of fluvial sediment. Quat. Geochronol. 2 (1-4), 367-372.

Tissoux, H., Toyoda, S., Falguères, F., Voinchet, P., Takada, M., Bahain, J.., Despriée, J., 2008. ESR dating of sedimentary quartz from two Pleistocene deposits using Al and Ti-centers. Geochronometria $30,23-31$.

Toyoda, S., Voinchet, P., Falguères, C., Dolo, J.M., Laurent, M., 2000. Bleaching of ESR signals by the sunlight: a laboratory experiment for establishing the ESR dating of sediments. Appl. Radiat. Isotopes 52 (5), 1357-1362.

Yokoyama, Y., Falguères, C., Quaegebeur, J.P., 1985. ESR dating of quartz from quaternary sediments: First attempt. Nucl. Tracks Rad. Meas. 10 (4-6), 921-928.

Zhu, R.X., Potts, R., Xie, F., Hoffman, K.A., Deng, C.L., Shi, C.D., Pan, Y.X., Wang, H.Q. Shi, R.P., Wang, Y.C., Shi, G.H., Wu, N.Q., 2004. New evidence on the earliest human presence at high northern latitudes in northeast Asia. Nature 431 (7008), 559-562. 